\title{
Reflections on informal physics education
}

\author{
Shane D Bergin \\ School of Education, University College Dublin, Dublin, Ireland
}

\begin{abstract}
Informal learning offers opportunities for physics - opportunities that I hope the physics education research (PER) community can co-define and engage with. This commentary piece is a personal reflection on this topic. It reflects, and builds on, my Physics Education Research Conference (PERC) 2019 presentation. Grounded in my personal experiences with informal physics education, my PERC presentation asked those present to collectively consider the values, practices, and people they associate with successful informal learning. Attendee comments are presented and discussed in ways that I hope the PER community will identify with and respond to. They suggest myriad opportunities that informal learning offers physics - opportunity to i) engage diverse groups of people in doing physics; ii) for physicists as a community; iii) to advance the field.
\end{abstract}

\footnotetext{
2019 PERC Proceedings edited by Cao, Wolf, and Bennett; Peer-reviewed, doi.org/10.1119/perc.2019.plenary.Bergin Published by the American Association of Physics Teachers under a Creative Commons Attribution 4.0 license. Further distribution must maintain attribution to the article's authors, cover page, and DOI.
} 


\section{INTRODUCTION}

There are significant and varied programs to increase the number of people who will study, or engage with, physics [1]. I often wonder why: is there an optimum number? Would bringing in more people improve physics? To what level do those targeted need to be educated? Are the main drivers for this increase purely economic? Should physics reflect on its own culture and norms when attempting to diversify those who identify as physicists? As a physicist who enjoys creating, running, and thinking about informal programs, I ask myself these questions a lot. It strikes me that funders (both public and private), as well as universities, who support informal learning primarily do so to increase the number of physicists. While, on the face of it, this goal sounds attractive, I feel it rather limits what informal learning can, or indeed should, be about.

I came to Physics Education Research Conference (PERC) 2019 wondering how the physics education research (PER) community viewed informal physics learning. I've written this article as a position paper - a commentary, or reflection, grounded in my PERC plenary and my associated interactions with attendees.

\section{INFORMAL PROGRAMS INFORMED BY VALUES}

\section{A. Positionality}

As with many people in the PER field, my career in physics has been somewhat non-traditional. While I enjoyed a day at the bench as much as the next physicist, the path of least resistance tended towards 'outreach', public engagement and education. Nevertheless, I very much consider myself a physicist and would, I hope, be seen as one too. This identity has been shaped primarily through informal physics education projects I have participated in and/or created. Perhaps a fortunate victim of geography, I had the opportunity to learn, teach, and do physics in places where people are chatty and where small communities, like physics, overlap with others. Coffee conversations with playwrights or artists were as likely as those with other scientists. Thus, a combination of personal disposition and available social structures has seen me practice, and reflect on, informal physics learning.

\section{B. Values-informed programs}

Twenty years on from the beginning of my undergraduate physics degree, my professional values inform, and are informed by, informal physics programs. I cite three below. I feel it important to stress that arriving at these valuesinformed programs has been, and continues to be, an iterative process.

\section{Working in diverse teams leads to diverse outcomes}

In 2013, I started DARTofPhysics [2] - a public campaign to spark city-wide conversations about physics in Dublin, Ireland. 'Physics adverts' (see Fig. 1) were placed on the metro, the DART, in places where Dubliners might otherwise see adverts for commercial products or services. Statements or questions like 'The Moon is escaping the Earth', 'We are all made of stardust', or 'Why does the metal pole feel colder the plastic seat?' were designed to pique interests and start conversations. DART passengers had opportunity to engage with these through our project website, through media partners, or with undergraduate physics students wearing DARTofPhysics t-shirts taking the DART train to, or from, College.

At the beginning of this campaign, I felt the appropriate project management style was to find grant money and hire the services I needed. I was wrong. This utilitarian approach limited DARTofPhysics to my views of physics and public perceptions of physics. I was fortunate that the designers, physics students and educators that worked with me, challenged me: a more diverse view of what the project was, and thus how it should work emerged. That diversity brought a sophistication I would not have achieved on my own or in a team where I 'hired' the help. In particular, I'd cite the importance of working with those who manage public events. On reflection, I feel sharing the control of your idea with those who share your values, but whose expertise is not the same as yours, may have been key to our shared success.

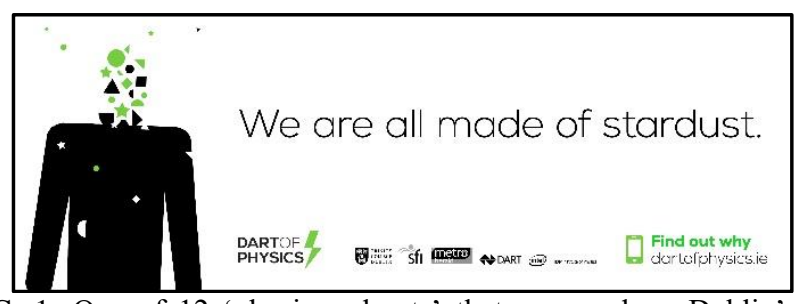

FIG. 1. One of 12 'physics adverts' that appeared on Dublin's DART train during DARTofPhysics.

In 2015, DARTofPhysics evolved to a 6-week City of Physics [3] campaign - building on the idea of sparking citywide conversations by placing physics slogans, physics art, podcasts, etc. in places it 'didn't belong'. As well as posters on trains, buses, city streets, and public places (shopping centres, libraries, schools, etc.), we projected images, such as live data from the Sun, onto the gable ends of large buildings at busy city intersections. City of Physics had a hack-the-city feel, as a team of academics, students, teachers, designers, and broadcasters brought physics to public spaces in the city centre. Encouraged by project partners from the tech sector, we stretched our partnerships further, working on ways to occupy public, or third [4], spaces in a way art might, rather than how advertising does - we imagined the 
constituent components of City of Physics as boundary objects, around which Dubliners could hang ideas and conversations. For the project team and I, the required interplay with city planners, other physicists, and Dubliners, was intriguing. Rather than enter a project with a preconceived notion of the physics that City of Physics should cover, the content was emergent and almost art-like. The interactions with project partners that led to City of Physics makes me think about the agency being an academic can bring, the beauty that can be found in abstract things like physics, and the complex attractions people can have with such abstraction.

\section{Informal physics programs don't just have to be about physics}

If I were not a physicist, I think I'd be a musician. Perhaps this explains how I found myself deep in discussion with the education team from the Irish National Concert Hall in my then-university's Science Gallery Café. Discussions on the physical nature of musical sound led to us creating an informal program that's now in its $5^{\text {th }}$ year and underpins many of my research activities and formal teaching. Quavers to Quadratics [5] sees primary school children play with ideas common to physics and music. They are led in their play by undergraduate physics and music students who work closely with children's class teachers. That partnership follows a co-teaching approach. Quavers to Quadratics is a collaboration between a national cultural institution (the National Concert Hall) and two universities (University College Dublin, where I and the other physicists involved are based, and Trinity College Dublin, where our music colleagues are based). A typical cycle of Quavers to Quadratics takes approximately 3 months with a mix of undergraduates visiting participating schools, and then those schools coming to the National Concert Hall for day-long workshops led by the undergraduates and primary teachers. While the curriculum of the program evolves with each new co-teaching cohort, typically we play with questions like 'why are musical instruments different shapes and sizes?' or 'how can we make musical sound?'.

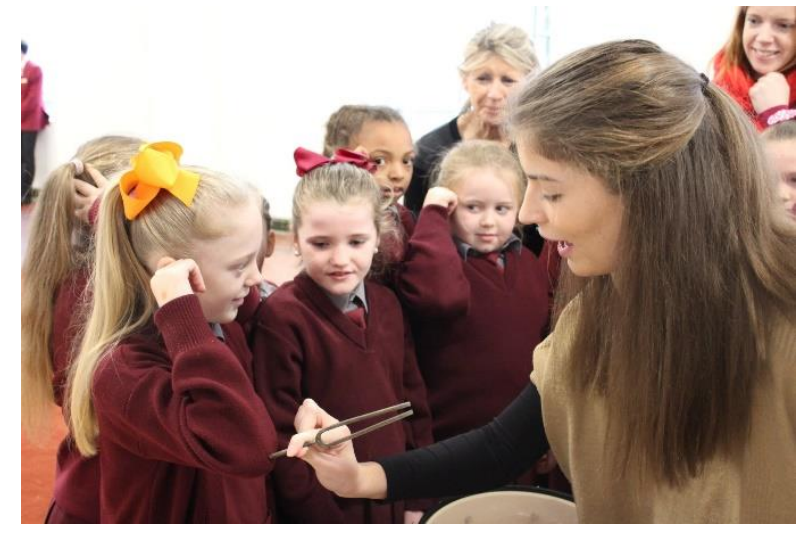

FIG. 2. Undergraduate student and primary school children playing with the idea of feeling sound.

I find it interesting how people interpret Quavers to Quadratics, with many feeling the need to classify it as either a physics program with music or vice versa. It's challenging to consider what it means to be both a music and physics program. It can easily lead, as it has for me, to consider the point of the program and why I wish to be involved. On reflection, I feel undergraduate agency has been the dominant factor in determining the trajectory of Quavers to Quadratics. While my initial role in the program saw me teach and lead the participating undergraduate students, my role has since evolved to one that has seen me step-back and support the undergraduates' community and associated practices. Despite the fact that the group of undergraduates associated with the programme has changed since the program's beginning, there has been a sense of communitylevel growth. Students think about the values they associate with Quavers to Quadratics: they think about what they're doing with respect to those values, and the tools, expertise, and people they may wish to engage with to improve, reflect, and learn.

In partnership with members of the PER community, we are looking at how participation, as educators in the program, affects the undergraduates physics students' identities. Quavers to Quadratics has changed how I relate to students, where professional bonds that are formed through informal physics are the basis of relationships that underpin formal education interactions I may have in lectures or labs.

\section{The way scientists work is as important as the claims scientists make}

With the rise of populist politics, 'alternative facts' have inveigled themselves into our vernacular. Facts are to be accepted, it seems, but only for now and only until a more attractive set comes along. In the associated scramble for who and what to believe, science has, I believe, positioned itself as a final arbiter of truth. This bothers me, for at the very core of the scientific process lies an acknowledgment of uncertainty. Science is wary of the absolute, and it is weary of conviction.

While I don't wish for one moment wish to give oxygen to the buffoonery of the those who peddle alternative facts, neither do I wish to see science sell itself short. The choice between facts and alternative facts is a false dichotomy, and the most rudimentary understanding of the scientific process bears this out. While this has informed my approaches to formal teaching (in particular, laboratory teaching), it too has led to informal learning projects that seek to emphasise the scientific process. Informal programs like Everyone Counts (a community-based project that sees children pose challenges of their own design in their local neighbourhood [6]) and 101 The Ways We Learn (a podcast series that explores the multifaceted ways different disciplines view the nature of learning [7]) explicitly explore how we arrive at 
scientific claims and the (un)certainty with which we offer them. These informal programs are grounded in my sense that the core strength of science resides in its operation and not its production.

I've suggested that science has backed itself into the present intellectual corner - how it has painted this selfimage of factuality and linear progression. I feel this is an area that informal science education practitioners might reflect on. Don't we have more 'outreach' than ever before? Isn't science accessible to the masses? Don't we have more students and scientists? With the frantic emergence of novel technology, the march of innovation seems unstoppable and globally we seem settled in the scientific paradigm. And in a way, we are - but I would argue that we can't see the scientific wood for the technological trees.

Science has had a media relations issue for quite some time. It trips over itself to present the newest cool thing in often dumbed down language. It promises never-ending impact and innovation to those who would control its funding. The problem remains however: despite huge investment to sell science, not many are buying. Science by press release results in people assuming the 'next big thing' is inevitable and predictable - that it is delivered unreflectively by an automaton in a white coat. People are loosely connected, at best, and apathetic at worst. Too few imagine science as theirs, as a human and cultural endeavour.

Science, perhaps, has not been pushed into a corner: it has backed itself in. And this is exactly where those who peddle alternative facts want it to be. An embattled and onedimensional science is one that is easily discredited and attacked. I realise I refer to science as a sentient and singleminded thing. And of course, it isn't. Science is developed and practised by people; we may have shared values underpinning our daily work but our motivations and our world-views are many and varied. This diversity doesn't trouble our practice, but it is central to our self-concept. Thus, while I believe that science has backed itself into a corner of absolutes, I don't believe that practising scientists are comfortable in that position: it's time we pushed back.

As the current socio-political climate of reflectiveness regarding knowledge and expertise gives scientists the perfect platform for revitalised conversation and renewed commitment, what I propose is not a doubling down on hardening distinctions (between fact and fiction, between science and fake science, or between the true and the alternative) but an opening up of honesty and transparency. What I would propose is a careful consideration of how we present ourselves and our discipline outside the lab and the academy. In this emerging, informal space the science educator is key, for they are the intermediaries that keep this dialogue open. We must celebrate our findings, of course, but we must celebrate our process and our conversation as well. We need not be afraid to let people see how the sausages are made.
In confident rejection of facts and facts alternative, I say let us embrace the awesome complexity of our working patterns. Let us embrace our failed experiments, our inspirations and imaginings, our checks and balances, and our glorious process of peer review.

\section{PER COMMUNITY RESPONSES}

Mindful of the myriad informal learning programs PERC attendees are associated with as participants, alumni, leaders, and/or researchers, my plenary presentation sought to provoke a community-level response. Grounded in personal experiences, groups of attendees engaged with three questions posed of them. Attendees used sticky-notes to voice their group's ideas. These were added to large posters displayed throughout PERC at the poster sessions. These fuelled discussions. Then, as in this article, I asked: can interesting questions emerge, that the PER community wish to engage in? The sections below are my reflection on the attendees' views. I'd hope conversations and ideas will bubble up from the PER community based on these. Should you wish to read all the comments, please refer to https://tinyurl.com/y34r86j2

\section{A. What does, or can, informal learning offer?}

I was struck by the overwhelmingly positive comments posted. Groups' responses were, broadly speaking, associated with freedom or novelty. The idea of 'breaking the rules' we might associate with formal learning, in terms of how and what we are taught, the reasons for learning, those who can be involved, etc. came to mind when I read phrases like 'you don't have to explain everything - leave people thinking', 'can lower barriers', or 'opportunity to play with real interests, that are connected to our lives'. Given my own interests with physics and music, I was drawn to notes that saw potential in the 'blurring of boundaries'. Might informal learning programs that do this reflect the complexity of our lives? While most reading this will have some sense of physics identity, they too will have myriad other identities that resonate with their interests, backgrounds, aspirations, etc. Nobody is just a physicist. I felt other comments had more of an agenda around ideas associated with public perceptions of science and who does science. 'Diverse thinking' or 'subverting the science identity' were intriguing, in terms of how informal learning may/could change physics.

\section{B. What does successful informal learning involve?}

Perhaps grounded in the sophisticated thinking PER has demonstrated around formal education, comments reflected a mix of affect, community, challenge, and learning. People spoke of 'joy', 'reward', 'delight', and 'surprise'. Community practices that were 'safe', 'porous', and 'where people are', were presented alongside opportunities, or 
challenges, to learners ('users define success and agency', 'to be yourself') and for us as physicists ('broadens definitions of science and learning'). While comments that mentioned learning were broad in scope, learning was not seen, I believe, as an outcome - ideas were shared of 'starting conversations', 'connections to self', 'future possibilities' and 'empowering yourself, for yourself, and not as a performance for a higher power structure'. I wonder whether thinking of informal learning in this way can help us think more about the nature of learning itself.

\section{What informal programs are you impressed with, or proud of? What makes them so?}

I felt that attendees' views could be spilt into two camps. Some referred to personality-driven or demo/exhibit programs while others were drawn more to those programs that went beyond the ideas of outreach, or communication, referring to 'agency', 'play', and 'community'. Perhaps mindful of the reality that the PER community are more focused on formal aspects of physics education, I was surprised that the number of programs offered by attendees was quite low (again, I acknowledge the exercise was more of a straw-poll than a scholarly exercise). That said, I'm keen to encourage readers to seek out practitioners of informal physics education and begin conversations. The PER community have a demonstrated capacity to explore varied aspects of learning physics - a capacity that refutes a practitioner/researcher dualism and instead embraces the complex identities, and associated worth, we bring to physics. I would contend that informal physics learning should be part of what we in PER do.

\section{Continued Conversations?}

While I consider myself relatively new to the PER community, I have a clear sense of the impacts it has made to physics and physicists. More seasoned members of the field rightly refer to the collective position people took some years back to establish the field and build community around values and infrastructure. At PERC2019 sessions, I was struck by the consideration people were giving to the field's views of informal physics learning. I'd very much hope my plenary, the diversity of parallel sessions, posters, etc. that responded to the 2019 PERC theme of 'Physics Outside of the Classroom: Teaching, Learning, and Cultural Engagement in Informal Physics Environments', will lead to continued conversations.

\section{CONCLUSIONS}

Through this commentary, I have made an appeal to the PER community to consider the inherent worth of informal physics learning. I have put forward my own position, in terms of informal programs I have created and also in relation to comments made by attendees at my PERC presentation. My career as a physicist who enjoys informal learning affords me the platform to say informal learning offers diverse and interesting ways to do, and think about, physics. I very much hope our community can respond to this through scholarly pursuits.

\section{ACKNOWLEDGMENTS}

I wish to acknowledge the students and colleagues who have co-organised, and researched, the informal programs described in this article. Full details can be found on the respective project websites. Thanks also to Science Foundation Ireland who have funded these programs through their 'Discover Programme'.

[1] https://www.informalscience.org/projects. Retrieved 8/6/2019.

[2] https://www.dartofphysics.ie Retrieved 8/6/2019

[3] https://www.cityofphysics.com Retrieved 8/6/2019

[4] W.M. Smith, Science Education from People for People: Taking a Stand(point) (Routledge, New York, 2009)

[5] https://tinyurl.com/yyy9tnkz Retrieved 8/6/2019

[6] https://tinyurl.com/yxjtwcsd. Retrieved 8/6/2019

[7] https://podcasts.apple.com/ie/podcast/101-the-ways-welearn/id1313104601 Retrieved 8/6/2019 